\title{
DAISY: An opportunity to improve access to information for all
}

\author{
APE 2008 (Academic Publishing in Europe)
}

\author{
Thomas Kahlisch* \\ Deutsche Zentralbücherei für Blinde zu Leipzig, Gustav-Adolf-Straße 7, 04105 Leipzig, Germany \\ Tel.: +49 341/7113 150; E-mail: thomas.kahlisch@dzb.de \\ URL: www.dzb.de; www.kahlisch.de
}

\begin{abstract}
Since 1996 public library services for the visually impaired round the world work closely with the ITC and the publishing industry in the DAISY consortium (www.daisy.org) towards international standards and technologies which are needed to improve access to information for the elderly and people with different reading disabilities.

The consortium's vision is "that all information, at time of release to the general population, be available in an accessible, highly functional, feature rich format and at no greater cost, to persons with print disabilities".

DAISY (Digital Accessible Information System) is an open standard for multimedia publishing, the version 3 has already become a national standard in the United States DAISY/NISO 2005 Z3986. The DAISY XML applications DTBook (to structure content in a Digital Talking Book) and NCX (for navigating multimedia contents) are used in OPS (Open Publishing Structure) 2.0 V. 1.0, published in summer 2007 by the IDPF (International digital Publishing Forum, www.idpf.org).
\end{abstract}

Today there are already more then 200,000 DAISY books available to people with reading disabilities all over the world. DAISY content is created from analogue tapes, read by narrators or converted from text files directly into the DTBook format. DAISY books can be played on special hardware players, different software applications and on accessible portable devices like PDAs or mobile phones.

In my presentation I will:

- describe the current projects of the DAISY Consortium,

- demonstrate examples of DAISY content,

- explain the benefits the publishing industry could gain from taking part in developing accessible information systems.

\section{Overview}

- Motivation

- MEDIBUS

- DAISY Consortium

- Technology and standards

- Projects

- Content and applications

\footnotetext{
* Dr. Thomas Kahlish is a Director of German Central Library for the Blind (DZB).
} 


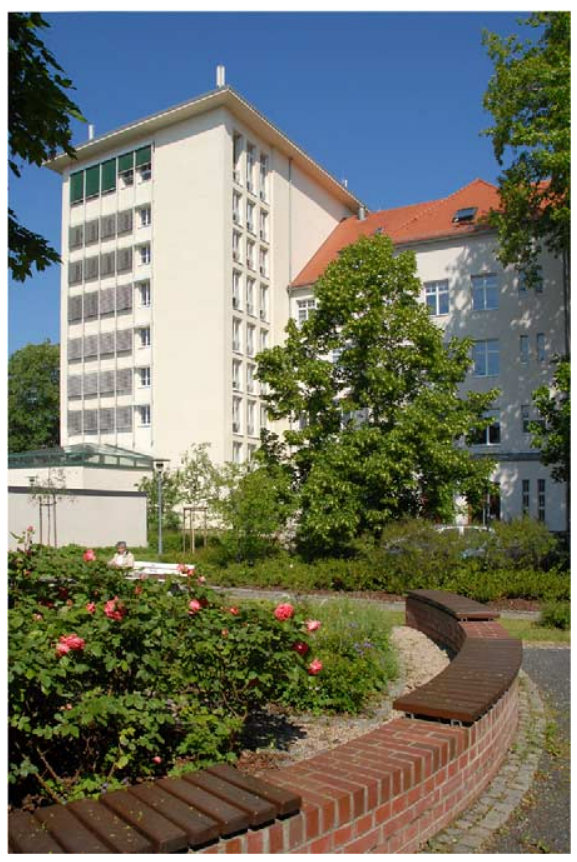

Fig. 1. DZB.

- Playback

- Example

- Cross-publishing

\section{Motivation}

DZB (Deutsche Zentralbücherei für Blinde zu Leipzig, see Fig. 1) is the oldest public library service for blind people in Germany. DZB was founded in 1894. Today, DZB is moving from being a special library service to a centre of accessible media design. The following timeline shows milestones of developments in accessible technology for blind and visually impaired people, see Fig. 2.

By using common technology like structured document processing and other cross publishing technologies it is possible to establish cooperative projects to increase access for all people with and without disabilities.

\section{MEDIBUS}

MEDIBUS is coordinating the production of accessible books for all German speaking countries (Germany, Austria and Switzerland).

This map shows all MEDIBUS sites in these countries, see Fig. 3.

Braille and talking books are produced by the member organizations of MEDIBUS. Currently, there are 42,000 titles in Braille, 50,000 talking books on compact cassettes and 20,000 DAISY books are available to the users. The books are delivered free of charge by the post. Patrons can use a catalogue to find new titles: www.medibus.info. 


\begin{tabular}{|c|c|c|c|c|}
\hline 1 & 1 & 1 & 1 & 1 \\
\hline $\begin{array}{l}1894 \\
\text { Manual } \\
\text { transformation } \\
\text { of Braille prints }\end{array}$ & $\begin{array}{l}1954 \\
\text { Narration of text } \\
\text { books on tape }\end{array}$ & $\begin{array}{l}1956 \\
\text { Preparation of } \\
\text { haptic reliefs }\end{array}$ & $\begin{array}{l}1970 \\
\text { Narration on } \\
\text { compact cassettes }\end{array}$ & $\begin{array}{l}1986 \\
\text { PC: scanning, OCR and } \\
\text { automatic Braille } \\
\text { translation }\end{array}$ \\
\hline 1 & $T$ & & 1 & \\
\hline 2002 & 2006 & & 2008 & \\
\hline $\begin{array}{l}\text { DAISY productio } \\
\text { and services }\end{array}$ & $\begin{array}{l}\text { Transfo } \\
\text { structu } \\
\text { into diff } \\
\text { access }\end{array}$ & $\begin{array}{l}\text { nation of } \\
\text { d documents } \\
\text { rent } \\
\text { le formats }\end{array}$ & $\begin{array}{l}\text { Publishers pro } \\
\text { information in } \\
\text { DAISY format? }\end{array}$ & \\
\hline
\end{tabular}

Fig. 2. Timeline.

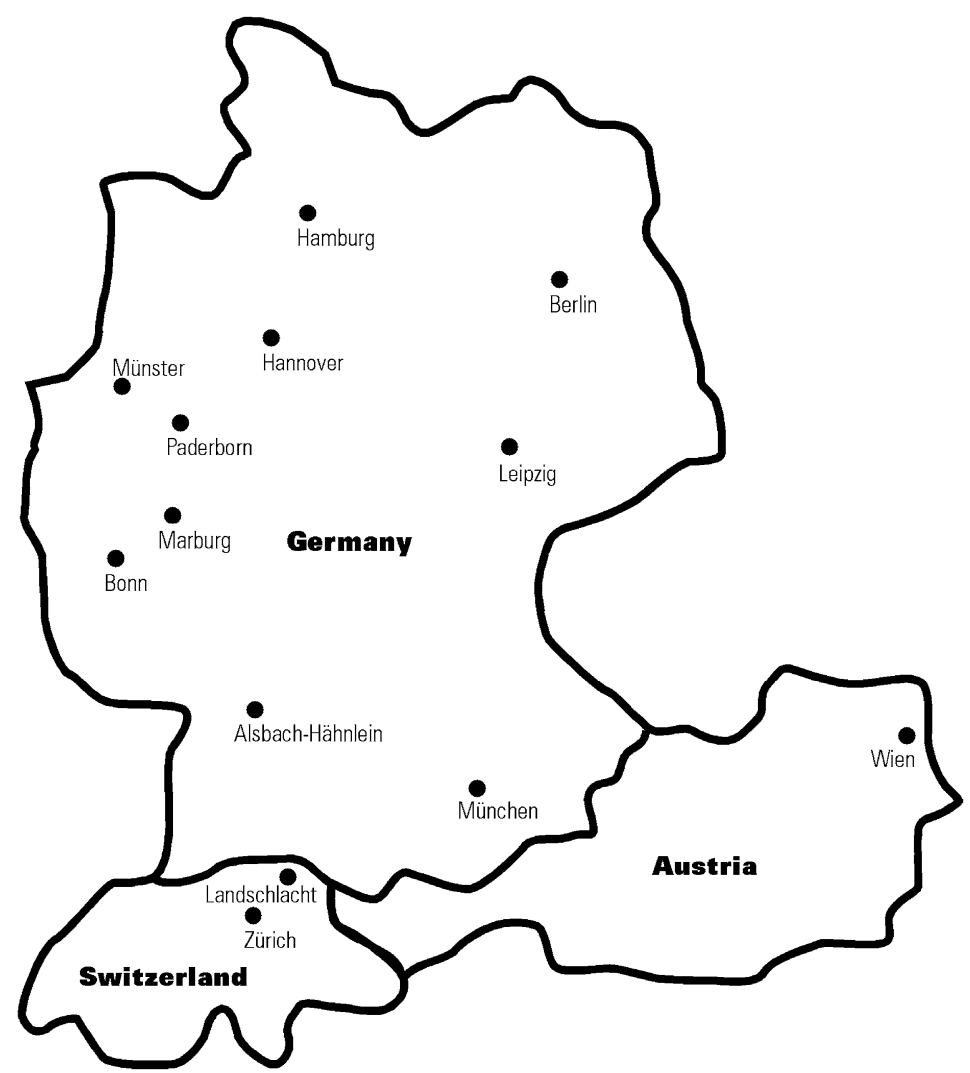

Fig. 3. MEDIBUS sites.

\section{DAISY Consortium}

DAISY (Digital Accessible Information System) is the name of a standard and the related technology that has been developed by the DAISY Consortium. The Consortium was founded in May 


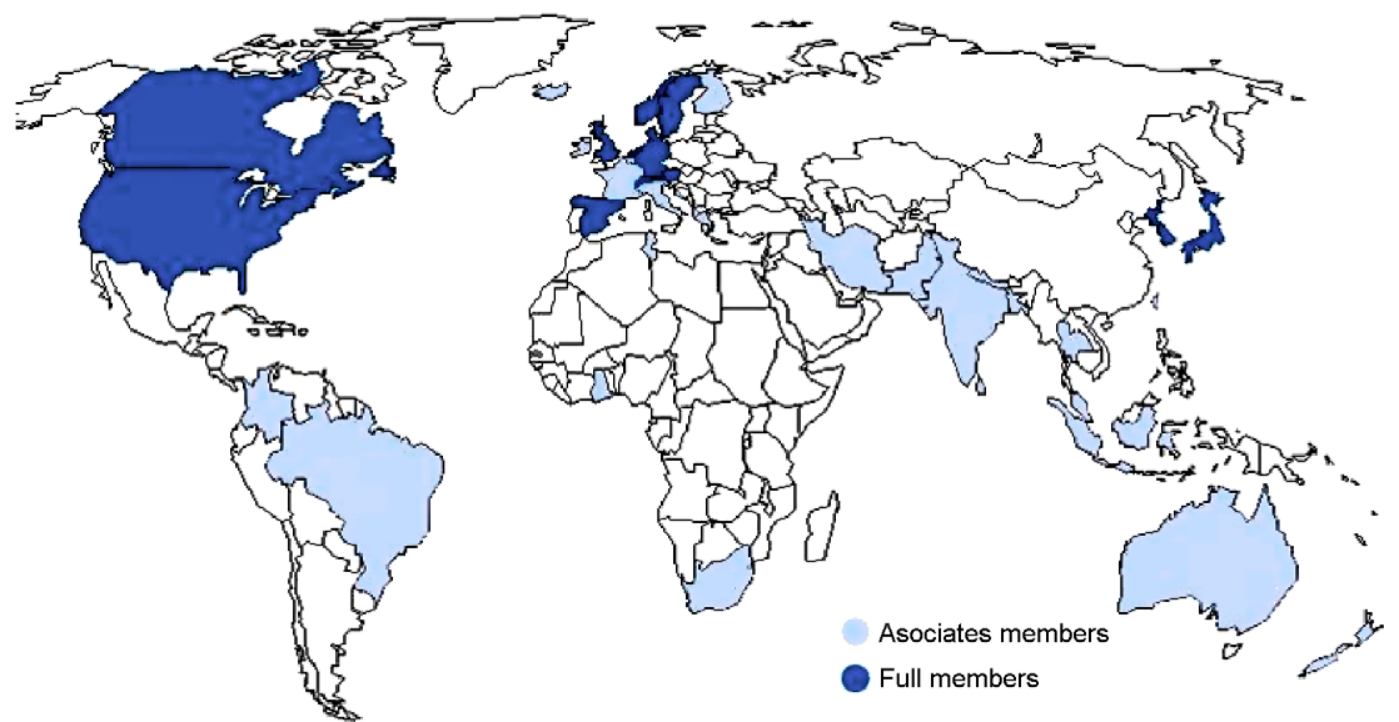

Fig. 4. DAISY member organizations.

1996 by talking book libraries to lead the worldwide transition from analogue to Digital Talking Books.

Now nearly 70 non-profit organizations make up the Consortium and actively promote the DAISY Standard. Most of the library services for the blind and visually impaired worldwide are members of the DAISY Consortium. The world map below shows all the countries that have full or associated member organizations in the Consortium, see Fig. 4.

The goal of the DAISY Consortium is:

Our vision is that all published information, at time of release to the general population, be available in an accessible, highly functional, feature rich format and at no greater cost, to persons with print disabilities (www.daisy.org).

\section{Technology and standards}

The DAISY Consortium is developing standards and technology for DTB (Digital Talking Books). DTB is a XML based format for accessible multimedia publishing.

Books, journals and a lot of other information can be marked up in the DAISY format. By using converting software, it is possible to translate a DAISY document into different accessible formats like Braille, large print or synthetic speech.

The following standards have been developed:

I 1996 DAISY Standard V. 1 (Proto type, Proprietary).

II 2002 DAISY Standard V. 2.02 (XHTML, talking book with TOC navigation).

III 2004 DAISY NISO Standard Z3986 (XML, schoolbooks and scientific publications).

In September 2007 IDPF (International Digital Publishing Forum) published the OPS V. 2.0 specification, which includes NCX and DTBook (part of Z3986). 


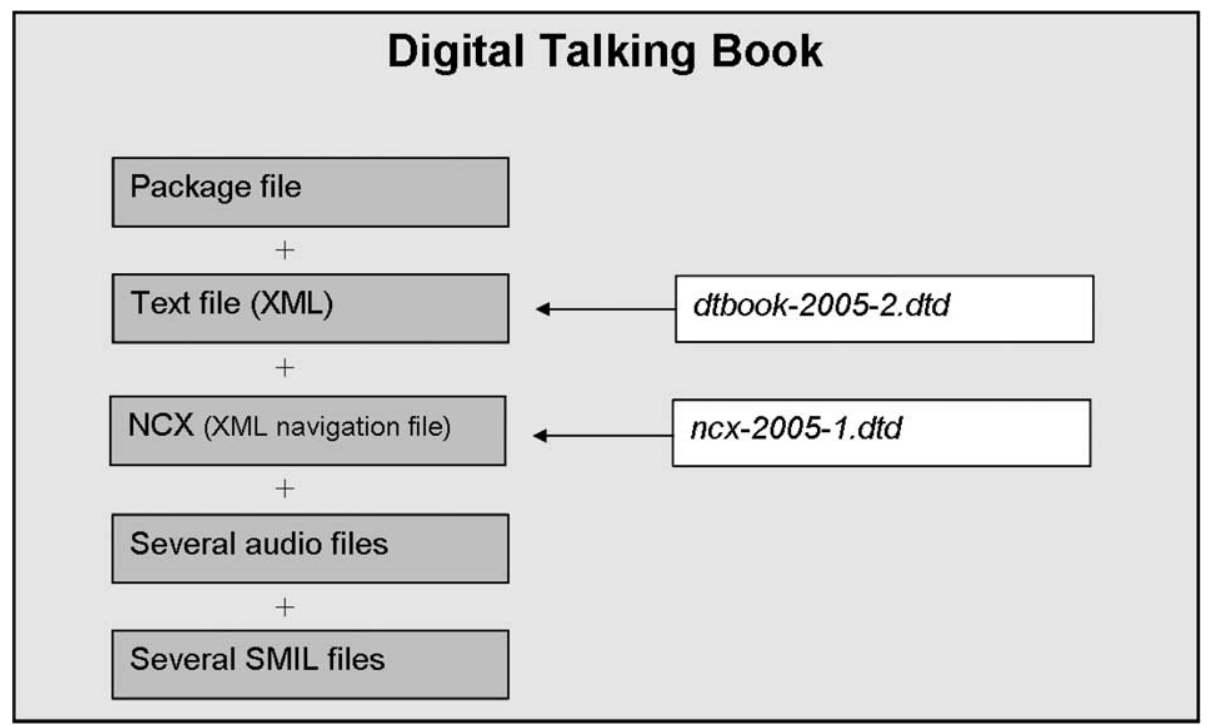

Fig. 5. NISO standard Z3986.

For more information see: www.idpf.org.

In November 2007 Microsoft announced a collaboration project with the DAISY Consortium. The name of the project is "Save as DAISY XML". Open software will be developed, to make it possible to store Microsoft office documents directly into the DAISY format.

For more information see: http://www.microsoft.com/presspass/features/2007/nov07/11-13daisy. mspx.

\subsection{DAISY/NISO Standard Z3986}

The DAISY V. 3 specification is a formal standard of the American standard organisation. Officially, the ANSI/NISO Z39.86 specifications for the Digital Talking Book.

Abstract:

This standard defines the format and content of the electronic file set that comprises a digital talking book (DTB) and establishes a limited set of requirements for DTB playback devices. It uses established and new specifications to delineate the structure of DTBs whose content can range from XML text only to text with corresponding spoken audio, to audio with little or no text. DTBs are designed to make print material accessible and navigable for blind or otherwise print-disabled persons.

The picture shows general file structure of a DTB and differences of DAISY V. 2.02 and DAISY/NISO Z3986, see Fig. 5.

\section{Projects}

The following projects have been established by the Consortium:

- DAISY for all 
- A support project to establish DAISY into developing countries;

- Braille in DAISY

- To develop facilities to translate content by using the Z3986 standard into different Braille formats;

- MathML modular extension for Z3986

- To include markup for mathematical expressions in an accessible format;

- DAISY and SVG

- To include appropriate markup for structured graphical information into the Z3986 standard;

- Urakaawa Project

- An open source API has been created, which can be used for Z3986 standard applications development;

- Online distribution

- API and facilities will be developed to standardize online distribution processes for DAISY content worldwide;

- DAISY Pipeline

- A Multi-Format-Converter is available to translate documents into the DAISY format.

\section{Content and applications}

Currently the DAISY V. 2.02 (talking books with navigation for searching and browsing into books) is in common use by the library services for the blind:

- More than 200,000 DAISY titles are available worldwide;

- By 2010 more than 30,000 titles will be available in Germany.

The advantages of the DAISY V. 2.02 books are:

- One book fits on one media;

- 40 hours audio on one CD;

- Users can search and browse the table of contents;

- Text and Audio synchronization is established by using SMIL.

The more complex books are provided in DAISY V. 3 Z3986.

DAISY V. 3. content is already being produced in the following projects:

- American publishers providing data in NIMAS format, a subset of Z3986.

- www.bookshare.org provides access to more than 50,000 DAISY documents in the USA only to users who have reading disabilities. 

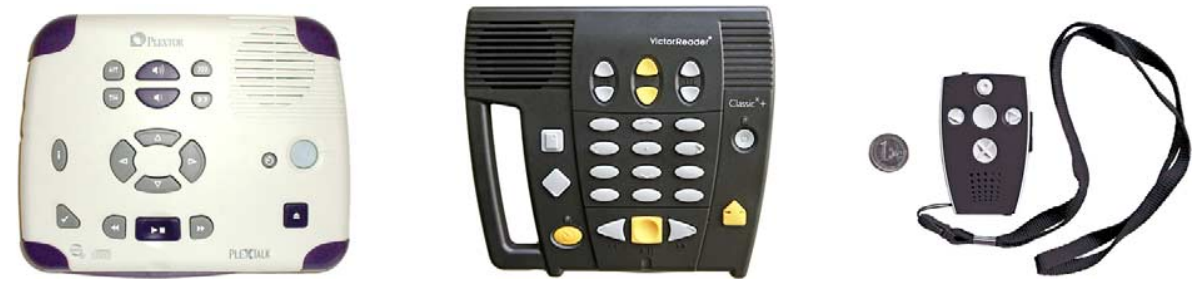

Fig. 6. DAISY player.

- www.Braillenet.fr and French publishers collaborate to translate information into Braille and other accessible formats.

\section{Playback}

It is possible to play DAISY books on special players, on a PC and on standard MP3 or DVD-Players. The special Players, PTN1, Victor Reader Stream and Milestone, are designed for the needs of people who cannot read displays and have only limited computer skills, see Fig. 6.

Software is: DAISY-Leser, AMIS and TpB. They can be used free of charge. They can be used to play the audio content, navigate into the book structure and to read the text of the book on the screen or on a refreshable Braille-display.

DAISY-Leser, playback software developed in DZB, can be downloaded from: www.daisyleser.de.

A current project at DZB is the development of DAISY playback software on mobile phones. DAISY2go is a player that will run on smart phones with the Simyon operating system.

Standard DVD and MP3 Players also play DAISY books, but they do not support the advanced DAISY features like the navigation and browsing capabilities. Usually these devices can only be used by reading out the information from the display. Blind people do not have access to these off the shelf products.

\section{Example}

Figure 7 shows an example of a DAISY book.

\section{Cross-publishing}

The great challenge of DAISY is that the format can be used for cross-publishing. By using the DAISY data as a single source file information can be translated into different formats that are suitable for the users, see Fig. 8.

An XML document provided by a publisher can be semi-automatically translated to Braille, large print or synthetic speech. The publisher can also use the XML document for different types of online and print publications. 


\section{Jon Krakauer: Into Thin Air}

Hörbuchinformation

The book is dedicated to Linda ...

Men play at traqedy...

\section{Introduction}

Dramatis Personae - Mount Everest - Spring 1996

Adventure Consultants Guided Expedition

Mountain Madness Guided Expedition

MacGillivrav Freeman IMAX/UWERKS Expedition

Iaiwanese National Expedition

Johannesbure Sunday Times Expedition

Alpine Ascents International Guided Expedition

International Commercial Expedition

Himalayan Guides Commercial Expedition

Swedish Solo Expedition

Norwegian Solo Expedition

New Zealand-Malaysian Guided Pumori Expedition

American Commercial Pumorillhotse Expedition

Nepali Everest Cleanina Expedition

Himalavan Rescue Association Clinic

Indo-Tibetan Border Police Everest Expedition

Jaoanese-Fukuoka Everest Expedition

Chapter One: Everest Summit - Mav 10 1996-29'028

feet

Chapter Iwo: Dehra Dun. India - 1852-2'234 feet

Fig. 7. Example of a DAISY book.

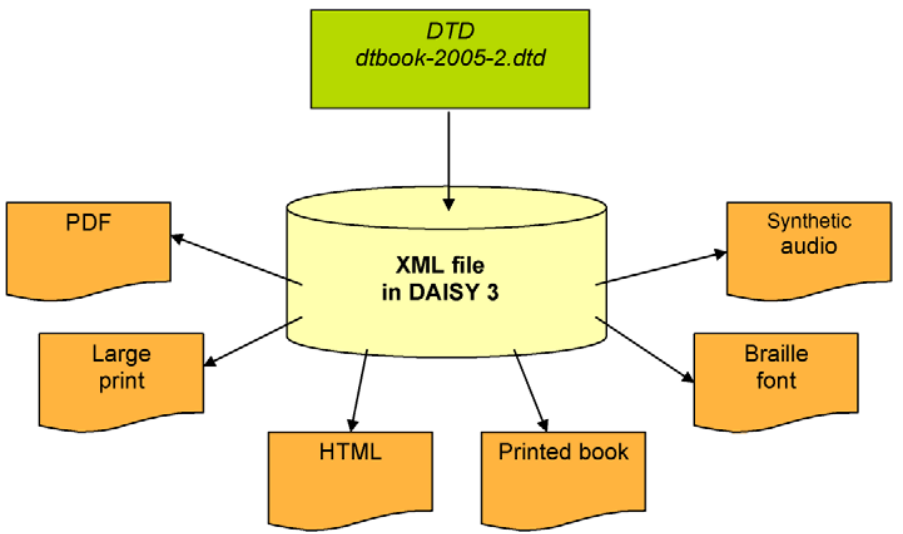

Fig. 8. Cross-publishing. 